\title{
Evaluation of Express Service Quality on Campus
}

\author{
Ji Xuehua \\ Business School, Beijing Wuzi University, Beijing, China
}

Email address:

2051758359@qq.com

To cite this article:

Ji Xuehua. Evaluation of Express Service Quality on Campus. American Journal of Engineering and Technology Management.

Vol. 3, No. 3, 2018, pp. 42-46. doi: 10.11648/j.ajetm.20180303.11

Received: May 24, 2018; Accepted: June 6, 2018; Published: June 29, 2018

\begin{abstract}
To satisfy individual needs of customers. The thesis analyses factors that affecting the quality of campus express mail service, in order to find out the best solution. On the foundation of the reality of campus express delivery, The Service Quality (SERVQUAL) and LSQ model applies to an index system with 20 indexes, Using questionnaires and factor analysis, the quality of campus express delivery is evaluated in three dimensions. With the index system, using fuzzy analytic hierarchy process (FAHP) to determine the index weight of campus express delivery, the result shows that there is still room for improvement in the quality of campus services. Suggestions are proposed to against existing problems and improve the overall quality of campus express delivery.
\end{abstract}

Keywords: Campus Express Delivery, Quality of Service, SERVQUAL Model, FAHP

\section{Introduction}

With the development of the Internet, Mobile shopping has become one of the ways of people. According to the data, the number of Web user reached 4.1 billion in 2015, it had an increase of $14.3 \%$ on the same time; the scale of Web user achieved 4.6 billion in 2016 , it had a rise of $11.2 \%$; Web user attained 5.0 billion in 2017 , it had an increase of $8.4 \%$; In 2018 , the total number of Web user will reach 5.3 billion, it will perform an argument of $6.1 \%$. It shows that Mobile shopping is of great significance to economic growth.

As demander of campus courier service, college students' evaluation of courier service quality have credibility and representativeness. Nowadays, campus express deliveries promote economic development and facilitate teachers-students activities, but it also exposes some problems such as delayed delivery and quality, because of the weak service consciousness of couriers [1]. results of low express services and big complaints [2]. It can be seen that campus have an urgent need for superior express services [3].

Many scholars take the quality of express delivery service as a research topic. For example, Xie Fang [4] analyzed customer's intention of repurchasing based on the original SERVQUAL model. Liu Zhiqiang [5] studied the service quality of customer perception, as well as measured express delivery quality from Empathy, Tangibility, Assurance,
Effectiveness, Responsiveness and Security. Zheng Jianing [6] used Cheng gong University City Express in Kunming as an example to quantify the perception of customer. Campus service has many differences from ordinary express delivery service, because it dispatches and few sent. Zhang Xiao [7] divided school express delivery into four types: picking, distribution, delivery from home and after-sales service, while used Stepwise regression, Principal component regression and Grey relational analysis to state the index system of Guangzhou University. Yao Jianhao [8] revealed the status of satisfaction and offered some suggestions to improve the quality of service. Liu Wenli [9] established a structural model based relational satisfaction to identify school service.

To sum up, research on campus express delivery service mainly focuses on analyzing problems and giving suggestions. However, the analysis on the combination of qualitative and quantitative research is not enough. Therefore, the paper uses SERVQUAL model to design a questionnaire and adopts Factor analysis. Then the index of school service quality was divided into three dimensions. At the same time, using fuzzy analytic hierarchy process to analyse the questionnaire survey data. Lately, promoting some relevant countermeasures to the high-quality development of campus express delivery. 


\section{Evaluation System of Campus Express Delivery}

\subsection{Analysis of Indicator System}

College students as campus service starting and end point, the processing of service is placing orders to personal preferences, the corresponding online shop commissions a third party to deliver goods. Finally, students can go to the campus express delivery network, smart courier cabinets or stalls, if you cannot be picked up by yourself, your commodities can be delivered by the courier company, the life cycle of Campus Express Service (as showed in Figure 1). Courier service is accompanied by the entire process of consumers placing orders and obtaining products. Therefore, when constructing the evaluation index of campus service, it may be based on the campus life cycle and combined with Market scientist Para Solman proposed the SERVQUAL model-Tangible, Reliability, Responsiveness, Assurance and Empathy, as well as the LSQ (Logistical service quality) model, it was proposed by MENTZER scholar in the United States in 2001. Then discussing 20 secondary symbols based on the first-level indicators of Express service evaluation system.

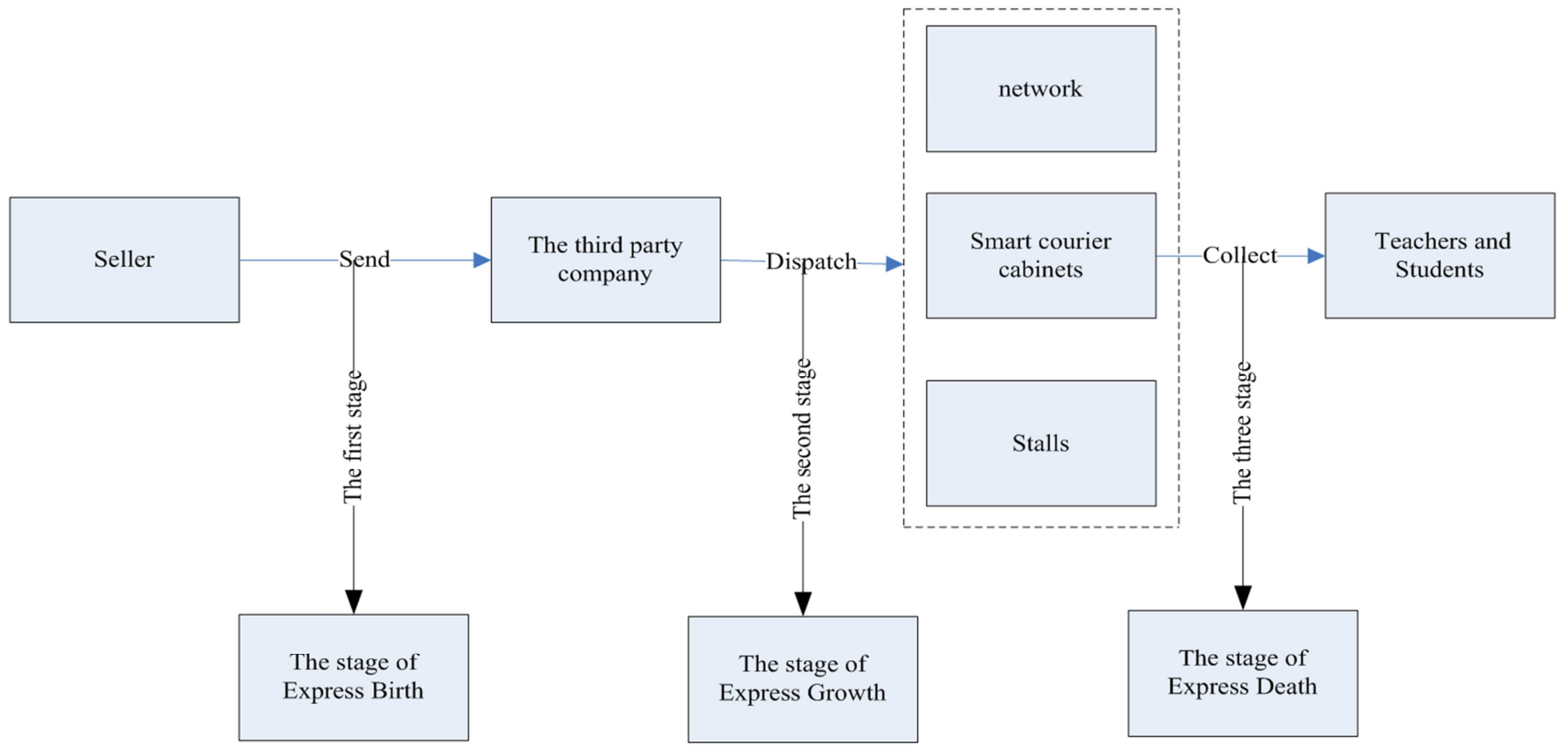

Figure 1. Life Cycle of Campus Express Service.

\subsection{Questionnaire Design}

The paper combines SERVQUAL and LSQ models to analyze the features of campus express delivery service, questionnaires use the Likert scale to design. Taking students and teachers as a subject and viewing "online-questionnaires" as survey method, the main content of investigation focuses on "Tangibility, Reliability, Responsiveness, Assurance and empathy" five areas. A total of 130 questionnaires are retrieved, 115 valid polls obtained, this recovery rate reached $88.46 \%$. By analysing, female students account for $59.3 \%$ and male students account for $40.7 \%$. It can know that female student are more frequent online shopping than male students, which is the main driving force for the rapid development of express delivery.

\subsection{Factor Analysis}

Using Software SPSS20.0 to carry out analysis on Factor
Analysis on the questionnaire and trying to find new dimensions of Campus Express Service Quality. The thesis select KMO and Bartlett to statistic date, the result comes out KMO is 0.703(higher than 0.7) and Bartlett's significant probability is 0.000 . It shows that survey date is suitable for Factor Analysis.

The paper aims to analyze campus service factors via Principal components assessment and Varimax rotation. Three similar elements are obtained through six iterations. It is summarized three type of Before service, In service, After service, the interpretative variance of the function is $19.908 \%$, $46.140 \%$ and $23.597 \%$, these three principal components are explained $89.646 \%$ of the total original variables. Through calculate we can obtain the indicators and weight of evaluation system of campus express service quality (as seen in Table 1).

Table 1. The indicators and weight of service quality system.

\begin{tabular}{llll}
\hline First-level indicators & Second-level indicators & $\begin{array}{l}\text { The coefficient of } \\
\text { factor analysis }\end{array}$ & $\begin{array}{l}\text { Second-level symbols account for the } \\
\text { proportion of primary indicators }\end{array}$ \\
\hline \multirow{2}{*}{ Before serviceU1 0.222} & Communication with consumer U11 & 0.294 & 0.094 \\
& The external image of courier U12 & 0.521 & 0.167 \\
\hline
\end{tabular}




\begin{tabular}{|c|c|c|c|}
\hline First-level indicators & Second-level indicators & $\begin{array}{l}\text { The coefficient of } \\
\text { factor analysis }\end{array}$ & $\begin{array}{l}\text { Second-level symbols account for the } \\
\text { proportion of primary indicators }\end{array}$ \\
\hline \multirow{14}{*}{ In service U2 0.515} & Matching existing between courier and facilities U13 & 0.197 & 0.063 \\
\hline & The level of using information system U14 & 0.307 & 0.098 \\
\hline & High efficiency U15 & 0.347 & 0.111 \\
\hline & Personal service U16 & 0.199 & 0.064 \\
\hline & Confidence of clients U17 & 1.023 & 0.327 \\
\hline & Smoothness of process 18 & 0.238 & 0.076 \\
\hline & Convenience U21 & 0.326 & 0.205 \\
\hline & Punctuality U22 & 0.049 & 0.031 \\
\hline & Excellent goods U23 & 0.190 & 0.119 \\
\hline & Reputable degree U24 & 0.165 & 0.104 \\
\hline & Reasonableness U25 & 0.207 & 0.13 \\
\hline & CoordinationU26 & 0.241 & 0.151 \\
\hline & Courier service attitude U27 & 0.156 & 0. 098 \\
\hline & Courier abilityU28 & 0.259 & 0.162 \\
\hline \multirow{4}{*}{ After service U3 0.263} & The efficiency of disputes U31 & 0.343 & 0.191 \\
\hline & Information feedback U32 & 0.355 & 0.198 \\
\hline & Advanced equipment U33 & 0.120 & 0.067 \\
\hline & Private information U34 & 0.975 & 0.544 \\
\hline
\end{tabular}

\section{Empirical Study}

The paper applies Fuzzy analytic hierarchy process (AHP) to solve the ambiguity of multi-indicators, because it can be judged with multi-factor and multi-level complex problems. By analysing the quality of services via qualitative, it avoided the impact of human subjective judgments on verification.

\subsection{Construct Factor and Evaluation Set}

From this Table, we can see that the evaluation of campus service quality consists of Before service, In service, After service, meanwhile each dimension is also composed of subdivision indicators. Including a first-level index $U=$ $\left\{\mathrm{u}_{1}, \mathrm{u}_{2}, \mathrm{u}_{3}\right\}=\{$ Before service, In service, After service $\}$; as well as a second-level index:

$$
\begin{gathered}
u_{1}=\left\{u_{11}, u_{12}, u_{13}, u_{14}, u_{15}, u_{16}, u_{17}, u_{18}\right\} ; u_{2}=\left\{u_{21}, u_{22}, u_{23}, u_{24}, u_{25}, u_{26}, u_{27}, u_{28}\right\} \\
u_{3}=\left\{u_{31}, u_{32}, u_{33}, u_{34}\right\}, \text { The evaluation level } V=\left\{v_{1}, v_{2}, v_{3}, v_{4}, v_{5}\right\}
\end{gathered}
$$

\{Very dissatisfied, Dissatisfied, General, Satisfaction, Very satisfied\},

$(40,50,60,70,80)$ used as the conversion score corresponding to the final score according to the degree of satisfaction.

\subsection{Determination of Index Weight}

\subsubsection{Build Fuzzy Judgment Coefficient Matrix}

Using the questionnaire survey data to obtain the judgment of the three evaluation words, the fuzzy judgment coefficient matrix of three indicators is $u_{1}, u_{2}, u_{3}$. The judgment coefficients of first-level signs form the fuzzy judgment matrix R.

$$
\mathrm{R}=r_{i j}=\left(\begin{array}{ccc}
r_{11} & r_{12} & r_{13} \\
r_{21} & r_{22} & 23 \\
\cdot & \cdot & \cdot \\
r_{m 1} & r_{m 2} & r_{m n}
\end{array}\right), r_{i}=\left\{r_{i 1}, r_{i 2}, r_{i 3} \ldots, r_{i n}\right\}
$$

\subsubsection{Determine the Weight of Indicator}

Impling Expert Rating Method and Delphi Method to assess indicators, It uses the 1-9 scale method of the analytic hierarchy process (as shown in Table 2), forming the first-level index judgment matrix $\mathrm{C}$ and the second-level index judgment matrix $c, c_{1}, c_{2}, c_{3}$.

$$
\mathrm{C}=\left[\begin{array}{cccc}
1 & 1 / 5 & 1 / 2 \\
5 & 1 & 1 / 4 \\
2 & 4 & 1
\end{array}\right] c_{1}=\left[\begin{array}{cccccccccc}
1 & 1 / 5 & 4 & 1 / 2 & 1 / 3 & 4 & 1 / 8 & 3 \\
5 & 1 & & 7 & 6 & 5 & 7 & 1 / 6 & 5 \\
1 / 4 & 1 / 7 & 1 & 1 / 5 & 1 / 6 & 1 / 2 & 1 / 9 & 1 / 3 \\
2 & 1 / 6 & & 5 & 1 & 1 / 3 & 5 & 1 / 8 & 4 \\
3 & 1 / 5 & 6 & 3 & 1 & 5 & 1 / 7 & 4 \\
1 / 4 & 1 / 7 & 2 & 1 / 5 & 1 / 5 & 1 & 1 / 9 & 1 / 3 \\
8 & 6 & 9 & 8 & 7 & 9 & 1 & 1 / 8 \\
1 / 3 & 1 / 5 & 3 & 1 / 4 & 1 / 4 & 3 & 7 & 1
\end{array}\right]
$$




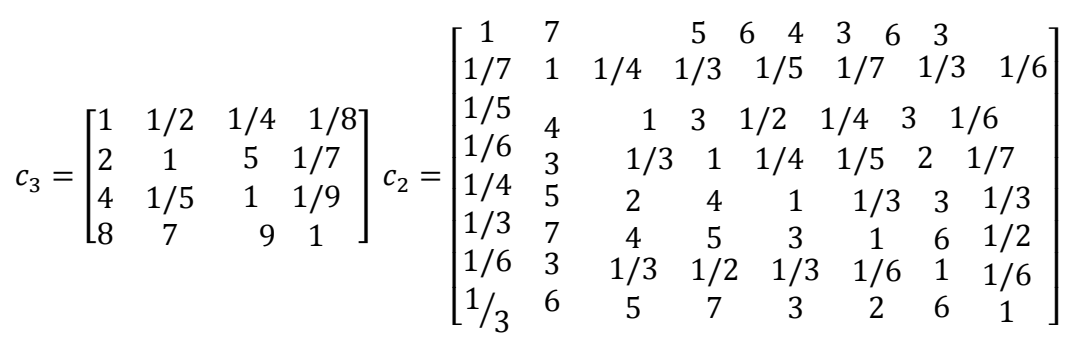

Table 2. Judgment matrix scale and its meaning.

\begin{tabular}{ll}
\hline Scaling & Definition and description \\
\hline 1 & This element is as essential as another element \\
3 & This element is slightly more important than another \\
5 & This element is more important than another element \\
7 & This element is more important than another element \\
9 & This element is more important than another \\
$2,4,6,8$ & Denotes the need for a compromise between the above two \\
$1 / \mathrm{aij}$ & standards \\
\hline
\end{tabular}

To calculate the relative importance of the indicators, it is necessary to analyze vector variables, Based on research and experimentation, the "square root method" that applied to normalise the vectors is given by:

$$
\begin{gathered}
M_{1}=\sqrt[n]{\prod_{j=0}^{n} a_{i j}} i=1,2, \ldots, n \\
W_{i}=M_{i} / \sum_{j=0}^{n} M_{i}
\end{gathered}
$$

Where: $a_{i j}=$ Each element of the matrix;

$M_{1}=$ The product of the elements of the matrix;

$W_{i}=M_{i}$ is normalized;

To sum up, it finally obtains the feature vectors $\mathrm{A}$ and $W_{1}, W_{2}, W_{3}$ of the judgment matrix.

$$
\mathrm{A}=\left(\begin{array}{l}
0.131 \\
0.304 \\
0.565
\end{array}\right) w_{1}=\left(\begin{array}{c}
0.076 \\
0.275 \\
0 \\
0.096 \\
0.142 \\
0 \\
0.331 \\
0.08
\end{array}\right) w_{2}=\left(\begin{array}{c}
0.337 \\
0 \\
0.071 \\
0.041 \\
0.102 \\
0.215 \\
0 \\
0.234
\end{array}\right) w_{3}=\left(\begin{array}{l}
0.053 \\
0.162 \\
0.081 \\
0.704
\end{array}\right)
$$

\subsection{Results}

Appling the fuzzy evaluation matrix to get the first-level index fuzzy comprehensive evaluation decision set $\mathrm{B}=\mathrm{U} \cdot \mathrm{W}$

$$
B_{1}=\left(\begin{array}{l}
0.047 \\
0.093 \\
0.516 \\
0.229 \\
0.116
\end{array}\right) B_{2}=\left(\begin{array}{c}
0.007 \\
0.077 \\
0.45 \\
0.695 \\
0.077
\end{array}\right) B_{3}=\left(\begin{array}{l}
0.075 \\
0.249 \\
0.408 \\
0.207 \\
0.062
\end{array}\right)
$$

Determine the fuzzy evaluation matrix: $\mathrm{P}=\mathrm{B} \cdot \mathrm{A}$

$$
\begin{gathered}
\text { So } \mathrm{P}=\mathrm{B} \cdot \mathrm{A}=\left(\begin{array}{lll}
0.131 & 0.304 & 0.565
\end{array}\right) \cdot\left(\begin{array}{cccccc}
0.047 & 0.093 & 0.516 & 0.229 & 0.116 \\
0.007 & 0.077 & 0.45 & 0.695 & 0.124 \\
0.075 & 0.249 & 0.408 & 0.207 & 0.062
\end{array}\right) \\
=\left(\begin{array}{lllll}
0.051 & 0.176 & 0.434 & 0.358 & 0.088
\end{array}\right)
\end{gathered}
$$

It can be concluded that $8.8 \%$ of customers are very satisfied with the service of campus express delivery; $35.8 \%$ of teachers and students are delighted; $43.3 \%$ of clients believe that the quality of campus service is ordinary; $17.6 \%$ of teachers and students are not satisfied; $5.1 \%$ of customers are not very delighted. According to the corresponding discounted score $(40,50,60,70,80)$, the final score of the current school express service quality is 68.98 . It shows that most teachers and students maintain a positive attitude towards school service, but it cannot be overlooked that about $22.7 \%$ of clients are not satisfied with current service.

\section{Suggestions}

The analysis shows that the quality of campus express delivery services needs continuous improvement. The key to improvement campus service is to cooperate with courier, schools and consumers.

\subsection{Recommendations for the Courier Company}

(1) Pay attention to the construction of logistics information system. To solve the problems of high costs, delays and loss of delivery mail, express delivery companies should strengthen the development of logistics information systems. The establishment of a timely and convenient information platform, it not only optimises the company's business processes, but also facilitates consumers to query for logistics information of products.

(2) Lay emphasis on the external image of the courier. The 
personal image and service attitude of couriers will directly affect consumer satisfaction and indirectly demonstrate the company's culture. Therefore, through training courier to establish a customer-centric service concept and enhance service quality, which would help improve the overall service image of the express delivery industry.

(3) Strengthen the optimisation of work processes. The high-quality operation of specific delivery processes should be based on scientific management, supporting by advanced technologies and ensured the construction of infrastructure and equipment. Therefore, courier companies should introduce advanced technologies to fill the gaps and match to service, it can provide the basis for the efficient delivery of express services.

\subsection{Suggestions for School}

From school' view, school as the interested representation of school customer, it not only carries out the integration and management of resources, but also takes on the responsibility of timely feedback and meets the basic needs of clients. Of course, the school should participate in the process of solving the problem of campus services and adopt active measures. From consumer's perspective, as a service object of campus express, teachers and students should respect courier. They should produce certification as much as possible while picking up the courier, the way would effectively avoid the misconduct and improve the efficiency. However, when personal rights are threatened, they should dare to complain to courier company or school management department.

\section{Conclusion}

Nowadays, the research on express delivery services mainly focuses on the macroscopic aspect and locks of systematic thinking. So this paper based on SERVQUAL and LSQ evaluation system, campus express service quality model is evaluated by Factor Analysis and Fuzzy Analytic Hierarchy. From the analysis, there is still room for improvement. The improvement of school express service depends on the deep cooperation among express delivery companies, school, teachers and students, as well as adopts scientific management methods. However, the result may be affected by the limited number of questionnaires. Can add the size of the survey to let the analysis more dependable and credible.

\section{Acknowledgements}

This study was supported by The National Key Research and Development Plan "Research and Application of Logistics Service Certification Scheme" (2016YFFo04105-1).

\section{References}

[1] YANG Xiaohong, "Study on the Operation Mode of the Campus Express Between Double Subjection," Journal of logistics technology, no. 7, pp. 35-37, 2014.
[2] CHEN Ping, YANG Jinwei, "Study on Quality Evaluation and Improvement Countermeasures of On-campus Express Delivery Service," Logistics Technology, no. 15, pp. 192-195, 2014.

[3] YU Ming, LI Guojun, "A Survey of University Students' Satisfaction to Express Service in Urumqi," Logistics Technology, no. 34, pp. 158-161, 2015.

[4] XIE Fang, "Empirical Research on the Relations between Online Shopping Customer Perceived Service Quality and Customer Repurchase Intention," The Theory and Practice of Finance and Economics, vol. 3, no. 37, pp. 123-127, 2016.

[5] LIU Zhiqiang, ZHANG Congyan, "Empirical Research on A Private Courier Company's service quality evaluation from the perspective of customer perception," Enterprise Economy, no. 7, pp. 88-92, 2014.

[6] ZHENG Jianing, "Who Moved My Information?"-Ownership and Protection of Express Service Information, Lanzhou Academic Journal, no. 8, pp. 150-156, 2016.

[7] ZHANG Xinghua, LIANG Kaihao, "Analysis of Factors affecting Campus Express Service Satisfaction," Economic Research Guide, no. 21, pp. 47-48, 2016.

[8] YAO Jianhao, GU Jing, "Study on the Satisfaction of Campus Delivery Service Based on Online Shopping: An example of Nanjing Xiao Zhuang University," Market Weekly (Theoretical research), no. 31, pp. 116-120, 2018.

[9] LIU Wenli, YE Xiaofei, CHEN Lin, "Campus express delivery optimization strategy based on satisfaction analysis: An example of Ningbo University," Journal of Ningbo University (Natural Science\& Engineering Edition), no. 1, pp. 40-42, 2018.

[10] CAO Xia, LI Ling, "Study on Evaluation System of Express Service Quality of Online Shopping based on SERVQUAL Model," Railway Transport and Economy, no. 8, pp. 93-98, 2015.

[11] Eleonora M, Laetitia D, Francois F, "Final deliveries for online shopping: The deployment of pickup point networks in urban and suburban areas," Research in Transportation Business\& Management, no. 11, pp. 23-31, 2014.

[12] Mentzer J T F, "Logistics Service Quality as a Segment-Customized Process," Journal of Marketing, vol. 8, no. 37, pp. 93-98, 2001.

[13] Park Y, Choi J K, Zhang A, "Evaluation competitiveness of air cargo express service," Transportation Research Part E: Logistics and Transportation Review, vol. 2, no. 45, pp. 321-334, 2009.

[14] Oliver R L, "Cognitive, Affective and Attribute Based of the Satisfaction Response," Journal of Consumer Research, vol. 3, no. 20 , pp. 418-430, 1993 .

[15] Hannah Nyambara Ngugi, James Wambua Kaluli, Zachary Abiero-Gariy, "Use of Expanded Polystyrene Technology and Materials Recycling for Building Construction in Kenya," American Journal of Engineering and Technology Management, vol. 2, no. 5, pp. 41-50, 2017. 